\title{
ChemComm
}

\section{Palladium-catalyzed cyclization of bromoenynamides to tricyclic azacycles: synthesis of trikentrin-like frameworks $\dagger$}

50,5187

Received 24th July 2013,

Accepted 15th August 2013

DOI: $10.1039 / c 3 c c 45634 j$

www.rsc.org/chemcomm

\author{
Craig D. Campbell, ${ }^{a}$ Rebecca L. Greenaway, ${ }^{a}$ Oliver T. Holton, ${ }^{a}$ Helen A. Chapman ${ }^{b}$ \\ and Edward A. Anderson*a
}

Palladium-catalyzed cascade cyclization of bromoenynamides equipped with an additional alkyne or ynamide substituent affords azatricyclic products. Using 5- to 7-membered ring tethers, this chemistry offers a regiospecific route to highly-functionalized azacycles. Elaboration to the trikentrin B skeleton is achieved from the arylsilane cyclization products.

The trikentrin and herbindole families of natural products, isolated from the marine sponges Trikentrion flabelliforme ${ }^{1 a}$ and Axinella sp., ${ }^{1 b}$ display a range of bioactivities including antimicrobial, antifeedant and cytotoxic properties. The heavily-substituted tricyclic indole systems which feature in these compounds (e.g. cis-trikentrin $\mathrm{B}$ and herbindole B, Scheme 1) represent a particular synthetic challenge that has inspired a number of elegant solutions. ${ }^{1}$

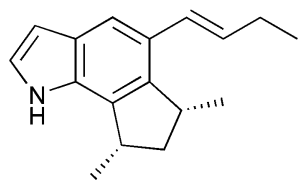

cis-trikentrin B

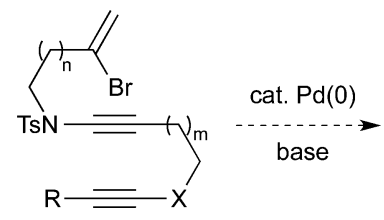

1
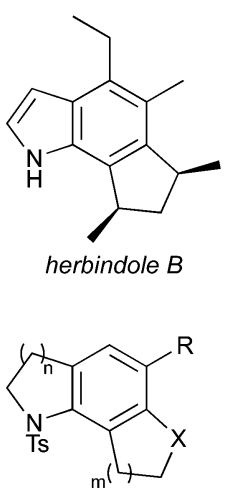

2
Scheme 1 cis-Trikentrin B, herbindole B, and the general bromoenynamide cyclization strategy.

\footnotetext{
${ }^{a}$ Chemistry Research Laboratory, University of Oxford, 12 Mansfield Road, Oxford, OX1 3TA, UK. E-mail: edward.anderson@chem.ox.ac.uk;

Fax: +44 (0)1865 285002; Tel: +44 (0)1865 285000

${ }^{b}$ Syngenta Ltd., Jealott's Hill International Research Centre, Bracknell, Berkshire, RG42 6EY, UK

$\dagger$ Electronic supplementary information (ESI) available: Experimental details, characterization and copies of ${ }^{1} \mathrm{H}$ and ${ }^{13} \mathrm{C}$ NMR spectra for novel compounds. See DOI: $10.1039 / \mathrm{c} 3 \mathrm{cc} 45634 \mathrm{j}$
}

In recent work, we have developed a number of routes to azabicycles from ynamides, including via ynamide carbopalladation. ${ }^{2}$ We have also reported a strategy to access the tricyclic 7,6,5-CDE ring cores of rubriflordilactones $\mathrm{A}$ and $\mathrm{B}$, which contain penta- and tetrasubstituted arenes respectively, through palladium-catalyzed cascade cyclization of bromoenediynes. $^{3}$ We noted that the combination of these two methodologies could provide access to the tricyclic indole core of the trikentrins, via cyclization of a bromoenynamide equipped with a remote alkyne $(\mathbf{1} \rightarrow 2$, Scheme 1$)$. The construction of fused ring arenes in this manner ${ }^{4}$ has rarely been employed in synthetic endeavours, ${ }^{3}$ and in the context of ynamides offers a useful alternative to the elegant cyclotrimerization methodology pioneered by Witulski, ${ }^{5}$ which has recently been applied to the herbindole system. ${ }^{1 c}$ This sequenced carbopalladation strategy offers advantages over intramolecular cyclotrimerization, where long tethers restrict the formation of larger rings, presumably due to competing intermolecular reactions. ${ }^{6}$ Here we describe the development of this novel ynamide chemistry, ${ }^{7}$ and its application to a number of azatricyclic systems, including aza- and benzazepine trikentrin analogues. Elaboration to the bis-desmethyltrikentrin B framework is also described.

We first set about the synthesis of a series of bromoenynamide alkynes suitable for cyclization, through the preparation of appropriate sulfonamide and bromoalkyne precursors (Scheme 2). The bromoalkenyl sulfonamides $\mathbf{3 a}$ and $\mathbf{3} \mathbf{b}$ were prepared from alkynes $\mathbf{4 a}$ and 4b via bromoboration/protodeborylation (with simultaneous Boc deprotection), whilst bromoalkynes $\mathbf{5 a}$ and $\mathbf{5 b}$ were synthesized from 1,6-heptadiyne by monosilylation then bromination. Both trimethylsilyl and benzyldimethylsilyl groups were installed, which we anticipated would enable various strategies for the attachment of trikentrin-like sidechains following cyclization. These building blocks were coupled using Hsung's copper-catalyzed methodology for ynamide formation, ${ }^{8}$ which provided ynamides 1a-c in moderate to good yield, albeit accompanied by a degree of desilylation in the case of TMSsubstituted diyne 5a. To further extend the cyclization methodology, we targeted a substrate featuring two ynamides, which would lead to an aza-trikentrin (pyrroloindoline) framework. The bis-ynamide 1d was readily prepared in four steps from 4 a by bromination/ carbamate deprotection (to afford the sulfonamide 6), followed by 

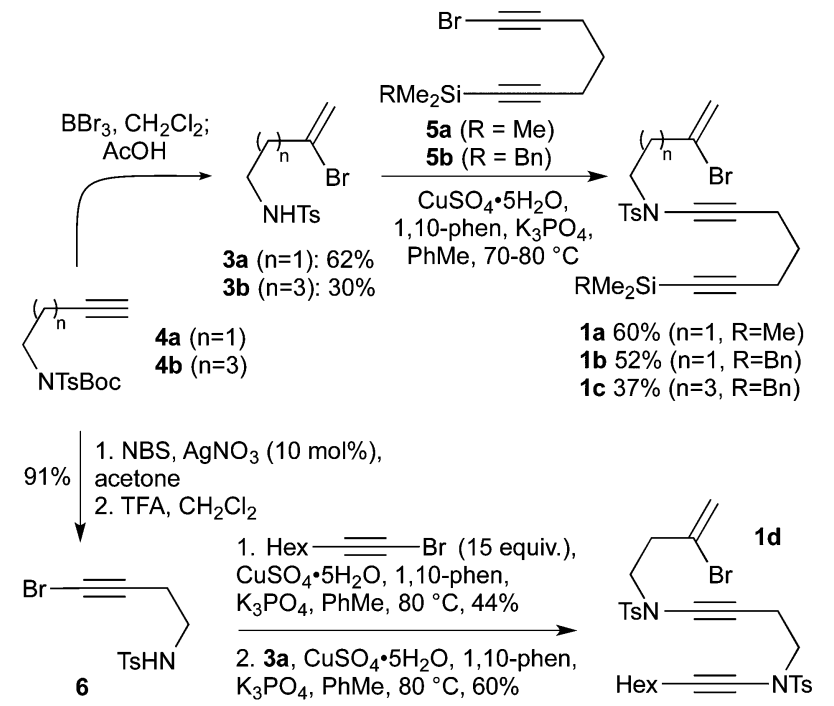

Scheme 2 Preparation of ynamide and bis-ynamide cyclization substrates.

sequential Hsung couplings - firstly with 1-bromo-oct-1-yne (used in excess to minimize intermolecular homocoupling of 6), then with sulfonamide $\mathbf{3 a}$.

With a selection of substrates in hand, the cascade cyclizations were investigated (Table 1). Using our previously reported conditions $\left(10 \mathrm{~mol} \% \mathrm{Pd}\left(\mathrm{PPh}_{3}\right)_{4}, \mathrm{Et}_{3} \mathrm{~N}, 0.017 \mathrm{M}\right.$ in $\left.\mathrm{MeCN}, 80{ }^{\circ} \mathrm{C}\right),{ }^{3}$ we were pleased to obtain the 5,6,5-tricyclic trikentrin frameworks $2 \mathbf{a}$ and $2 \mathbf{b}$ in excellent yields ( $90 \%$, entries 1 and 4 ). The catalyst loading could be lowered to $5 \mathrm{~mol} \%$ with a slight reduction in yield (entries 2 and 5); however, by increasing the concentration (to $0.16 \mathrm{M}$ ), catalytic efficiency was restored, with 2 a isolated in $88 \%$ yield (entry 3 ).

Cyclization to the challenging 7,6,5-tricyclic analogue of the trikentrin framework was next attempted. At higher catalyst loading and dilution, the desired tricycle $2 \mathbf{c}$ was obtained as a component of a complex mixture (entry 6). However, by performing this reaction at higher concentration, $2 \mathbf{c}$ was formed as the sole product in excellent yield (entry 7), a result that highlights the advantages of the sequenced carbopalladation strategy. Finally, diynamide 1d was subjected to the range of reaction conditions (entries 8-10). To our delight, tricycle $\mathbf{2 d}$, which represents the first example of such a pyrroloindoline framework, was isolated in high yield when reacted at the higher concentration (70\%, entry 10$)$.

With efficient access to azatricycles established, we aimed to demonstrate the utility of the methodology by preparing a natural product analogue - bis-desmethyl-trikentrin B 13 (see Scheme 3) from the 5,6,5-indolines $\mathbf{2 a}$ or $\mathbf{2 b}$. This required installation of the requisite butenyl sidechain, and conversion of the protected indoline to the free indole. For the former of these tasks, we recognised the synthetic value of the silane present in $\mathbf{2 a} \mathbf{a} \mathbf{b}$, which enables a variety of sidechain attachment strategies. We first addressed Hiyama crosscoupling of $\mathbf{2 b}$, which offers a direct route to the butenyl substituent and is an attractive alternative to other coupling methods (e.g. Stille, Suzuki) due to the low toxicity of silicon and its stability to multistep synthesis. ${ }^{9}$ To our knowledge, no Hiyama couplings between arylbenzyl dimethylsilanes and alkenyl halides have been reported, with only the reverse process being described (i.e. the coupling of alkenylbenzyldimethylsilanes with aryl halides). ${ }^{10}$
Table 1 Bromoenynamide-alkyne cascade cyclizations ${ }^{a}$

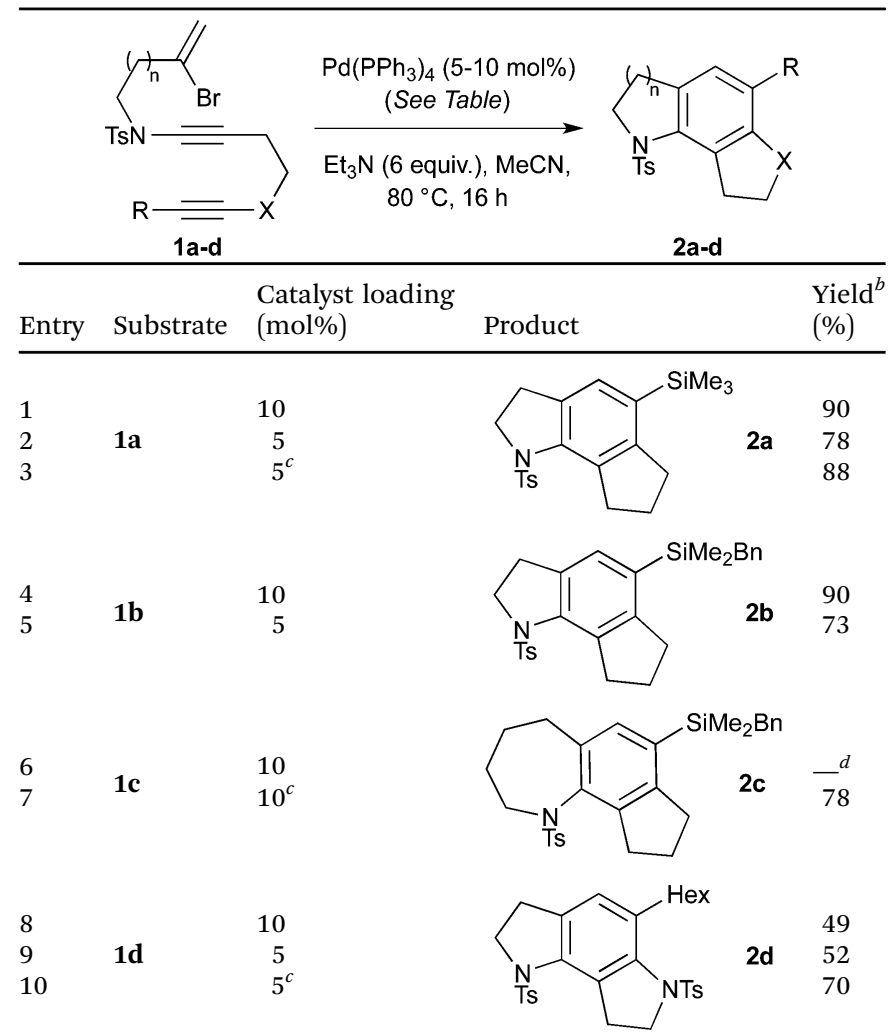

${ }^{a}$ Reaction concentration $0.017 \mathrm{M}$ unless indicated otherwise. ${ }^{b}$ Isolated yield. ${ }^{c}$ Reaction concentration $0.16 \mathrm{M} .{ }^{d}$ Complex mixture.

Standard conditions for the coupling of alkenyl benzyldimethylsilanes (TBAF, $\mathrm{Pd}_{2} \mathrm{dba}_{3} \cdot \mathrm{CHCl}_{3}$ or $\left.\mathrm{Pd}(\mathrm{dba})_{2}\right){ }^{10}$ using either $\beta$-styrenyl iodide $7 \mathbf{a}$ or butenyl iodide $\mathbf{7 b}$ as the halide partner, afforded no cross-coupling product (Table 2, entries 1 and 2). As benzylsilanes are 'safety-catch' silanols, and indeed are hydrolysed to the latter on treatment with TBAF, alternative conditions for the coupling of alkenylsilanols ${ }^{11}$ were also investigated, without success (entry 3). In all of these trials, mixtures of silanol, disiloxane, and desilylated arene were recovered, ${ }^{12}$ suggesting that the aryl silanol revealed on unmasking of the benzylsilane was resistant to transmetallation. The addition of $\mathrm{Ag}_{2} \mathrm{O}$ has been reported by Hiyama to accelerate transmetallation, ${ }^{13}$ and we were delighted to find that the coupling of styrenyl iodide 7a under these conditions smoothly afforded the styrenyl trikentrin framework 8a (68\%). Disappointingly, only desilylated arene was returned on attempted coupling with butenyl iodide $\mathbf{7 b}$, which for this study presented an insurmountable limitation.

A more classical route to install the butenyl sidechain was thus developed (Scheme 3). ${ }^{14}$ Aryltrimethylsilane $2 \mathrm{a}$ was subjected to a Friedel-Crafts acylation, which proceeded with exclusive ipso-selectivity to give ketone 9 (79\%). This ketone then underwent a high-yielding reduction-dehydration sequence to deliver the targeted butenyl sidechain (8b). Completion of the synthesis now required indoline detosylation and oxidation to reveal the indole moiety. However, all attempts to oxidise $\mathbf{8 b}$ to the corresponding sulfonyl indole were unsuccessful, leading mainly to degradation. ${ }^{15}$ Inverting this sequence of events resolved this issue; although $\mathrm{Mg} / \mathrm{MeOH} / \mathrm{sonication}$ (which is usually effective for such detosylations) ${ }^{2 a, 16}$ effected partial deprotection 
Table 2 Hiyama cross-coupling of arylsilane $\mathbf{2 b}$

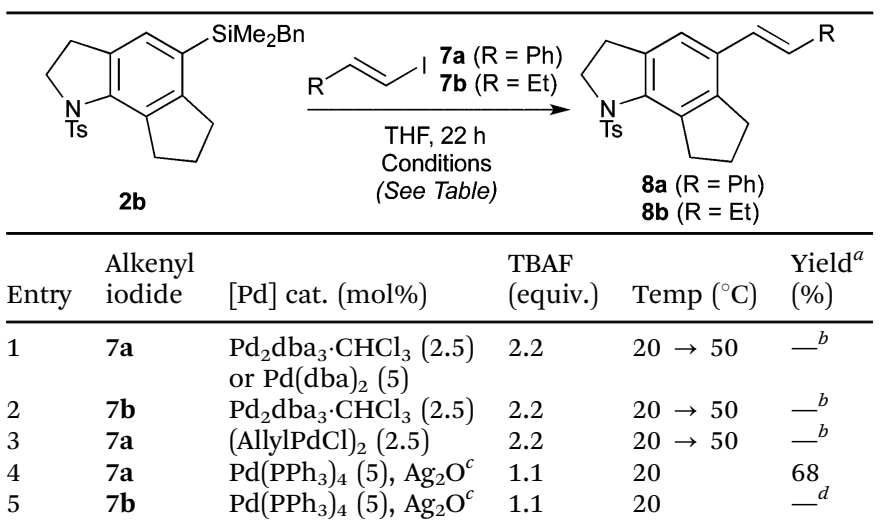

${ }^{a}$ Isolated yield. ${ }^{b}$ A mixture of silanol, disiloxane, and desilylated arene was recovered. ${ }^{c} 1.1$ equiv. $\mathrm{Ag}_{2} \mathrm{O} .{ }^{d}$ Desilylated $2 \mathrm{~b}$ was isolated $(67 \%)$.
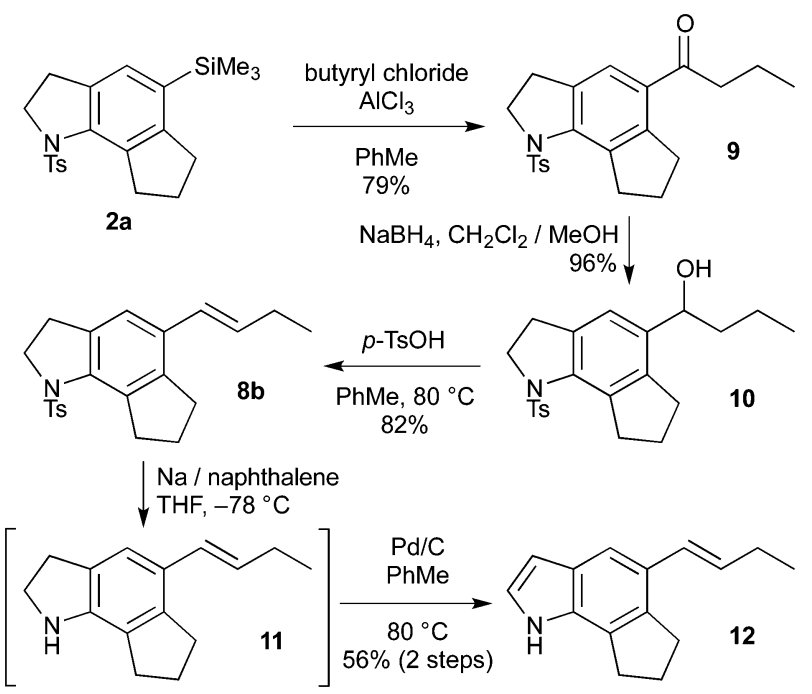

Scheme 3 Synthesis of bis-desmethyl-trikentrin B.

$(<25 \%)$, treatment of $\mathbf{8 b}$ with sodium naphthalenide gave the deprotected indoline $\mathbf{1 1}$ with high efficiency. Somewhat surprisingly, 11 underwent rapid aerobic decomposition, presumably due to the indoline-enhanced reactivity of the electron-rich styrene, ${ }^{17}$ and isolation of the pure indoline proved difficult. However, we were pleased to find that direct dehydrogenation of the crude indoline using $\mathrm{Pd} / \mathrm{C}$ in degassed toluene completed the synthesis, giving bis-desmethyltrikentrin $\mathbf{1 2}$ in good yield over the two steps.

In conclusion, we have developed a facile method for the preparation of azatricycles from bromoalkenyl ynamides. The reaction enables formation of five- to seven-membered rings, and offers an attractive alternative to cyclotrimerization strategies. The utility of this chemistry is demonstrated by installation of the trikentrin B alkenyl sidechain in a further four steps using Friedel-Crafts ipsosubstitution of the arylsilane cyclization products. As an alternative, we report the first example of an alkenyl iodide/arylbenzylsilane Hiyama cross-coupling, which affords a styrenyl-trikentrin analogue.

We thank the EPSRC (EP/H025839/1, CDC; EP/E055273/1, Advanced Research Fellowship to E.A.A.), and Syngenta Ltd. for a studentship (to R.L.G.).

\section{Notes and references}

1 For recent approaches to the trikentrins and herbindoles, see: (a) I. R. M. Tébéka, G. B. Longato, M. V. Craveiro, J. E. de Carvalho, A. L. T. G. Ruiz and L. F. Silva, Chem.-Eur. J., 2012, 18, 16890; (b) W. Liu, H. J. Lim and T. V. RajanBabu, J. Am. Chem. Soc., 2012, 134, 5496; $(c)$ N. Saito, T. Ichimaru and Y. Sato, Org. Lett., 2012, 14, 1914. For a review and references to earlier syntheses: (d) L. F. Silva, Jr., M. V. Craveiro and I. R. M. Tébéka, Tetrahedron, 2010, 66, 3875.

2 (a) R. L. Greenaway, C. D. Campbell, H. A. Chapman and E. A. Anderson, Adv. Synth. Catal., 2012, 354, 3187; (b) R. L. Greenaway, C. D. Campbell, O. T. Holton, C. A. Russell and E. A. Anderson, Chem.-Eur. J., 2011, 17, 14366; (c) P. R. Walker, C. D. Campbell, A. Suleman, G. Carr and E. A. Anderson, Angew. Chem., Int. Ed., DOI: 10.1002/anie.201304186. For other examples of ynamide carbopalladation, see: (d) S. Couty, B. Liegault, C. Meyer and J. Cossy, Tetrahedron, 2006, 62, 3882; (e) S. Couty, C. Meyer and J. Cossy, Tetrahedron Lett., 2006, 47, 767; $(f)$ S. Couty, B. Liegault, C. Meyer and J. Cossy, Org. Lett., 2004, 6, 2511.

3 (a) M.-C. A. Cordonnier, S. B. J. Kan and E. A. Anderson, Chem. Commun., 2008, 5818; (b) S. S. Goh, H. Baars, B. Gockel and E. A. Anderson, Org. Lett., 2012, 14, 6278. For recent reviews of palladium-catalyzed cascade processes, see: $(c)$ T. Vlaar, E. Ruijter and R. V. A. Orru, Adv. Synth. Catal., 2011, 353, 809; (d) E. A. Anderson, Org. Biomol. Chem., 2011, 9, 3997.

4 For the development of bromoenediyne cyclizations, see: $(a) \mathrm{W}$. M. Tokan, F. E. Meyer, S. Schweizer, P. J. Parsons and A. de Meijere, Eur. J. Org. Chem., 2008, 6152; (b) H. Henniges, F. E. Meyer, U. Schick, F. Funke, P. J. Parsons and A. de Meijere, Tetrahedron, 1996, 52, 11545; (c) E. Negishi, L. S. Harring, Z. Owczarczyk, M. M. Mohamud and M. Ay, Tetrahedron Lett., 1992, 33, 3253.

5 (a) B. Witulski and T. Stengel, Angew. Chem., Int. Ed., 1999, 38, 2426; (b) B. Witulski, T. Stengel and J. M. Fernández-Hernández, Chem. Commun., 2000, 1965; (c) B. Witulski and C. Alayrac, Angew. Chem., Int. Ed., 2002, 41, 3281. For recent examples of ynamides in [2+2+2] cyclization, see: (d) P. Garcia, Y. Evanno, P. George, M. Sevrin, G. Ricci, M. Malacria, C. Aubert and V. Gandon, Chem.-Eur. J., 2012, 18, 4337; (e) F. Nissen, V. Richard, C. Alayrac and B. Witulski, Chem. Commun., 2011, 6656. See also ref. $1 c$.

6 For a recent review, see: S. Kotha, E. Brahmachary and K. Lahiri, Eur. J. Org. Chem., 2005, 4741. See also ref. $3 b$.

7 For comprehensive reviews of ynamide chemistry, see: $(a)$ Y. Zhang, K. A. DeKorver, H. Y. Li, A. G. Lohse, R. Hayashi, Z. Lu and R. P. Hsung, Chem. Rev., 2010, 110, 5064; (b) G. Evano, A. Coste and K. Jouvin, Angew. Chem., Int. Ed., 2010, 122, 2902.

8 X. Zhang, Y. Zhang, J. Huang, R. P. Hsung, K. C. M. Kurtz, J. Oppenheimer, M. E. Petersen, I. K. Sagamanova, L. Shen and M. R. Tracey, J. Org. Chem., 2006, 71, 4170.

9 For reviews of Hiyama cross-coupling, see: $(a)$ H. F. Sore, W. R. J. D. Galloway and D. R. Spring, Chem. Soc. Rev., 2012, 41, 1845; (b) Y. Nakao and T. Hiyama, Chem. Soc. Rev., 2011, 40, 4893; (c) S. E. Denmark and J. H.-C. Liu, Angew. Chem., Int. Ed., 2010, 49, 2978.

10 (a) B. M. Trost, M. R. Machacek and Z. T. Ball, Org. Lett., 2003, 5, 1895; (b) S. E. Denmark and S. A. Tymonko, J. Am. Chem. Soc., 2005, 127, 8004; (c) S. E. Denmark and S. Fujimori, J. Am. Chem. Soc., 2005, 127, 8971; (d) S. E. Denmark and J. H.-C. Liu, J. Am. Chem. Soc., 2007, 129, 3737; (e) Y. Nishihara, D. Saito, K. Tanemura, S. Noyori and K. Takagi, Org. Lett., 2009, 11, 3546; $(f)$ C. Morrill and N. S. Mani, Org. Lett., 2007, 9, 1505.

11 (a) S. E. Denmark and L. Neuville, Org. Lett., 2000, 2, 3221; (b) S. E. Denmark and W. J. Pan, J. Organomet. Chem., 2002, 653, 98. 12 See the ESI $\dagger$ for details.

13 (a) K. Hirabayashi, J. Kawashima, Y. Nishihara, A. Mori and T. Hiyama, Org. Lett., 1999, 1, 299; (b) K. Hirabayashi, A. Mori, J. Kawashima, M. Suguro, Y. Nishihara and T. Hiyama, J. Org. Chem., 2000, 65, 5342.

14 Alternative strategies, such as the use of ynamides already featuring the trikentrin B sidechain, were not investigated in this study, which targeted a system enabling skeletal diversification at a late stage.

15 Oxidation using $\mathrm{MnO}_{2}, \mathrm{Mn}(\mathrm{OAc})_{3}$, DDQ, or AIBN/NBS led to complete degradation of material; $\mathrm{Co}($ salen $) / \mathrm{O}_{2}$ led to no reaction.

16 G. H. Lee, I. K. Youn, E. B. Choi, H. K. Lee, G. H. Yon, H. C. Yang and C. S. Pak, Curr. Org. Chem., 2004, 8, 1263.

17 Aldehyde-containing byproducts, presumably arising from cleavage of the alkene sidechain, were noted in this decomposition process. 